\title{
Referral patterns to an ophthalmic outpatient clinic by general practitioners and ophthalmic opticians and the role of these professionals in screening for ocular disease
}

\author{
R J Harrison, J M Wild, A J Hobley
}

Burton General Hospital, Burton-on-Trent, Staffordshire DE14 3QH R J Harrison, FRCS, consultant ophthalmologist

\section{Department of Vision}

Sciences, Aston

University, Birmingham B4 7ET

$\mathrm{J} M$ Wild, PHD, lecturer

A J Hobley, MSC, clinical demonstrator

Correspondence to: Miss Harrison.

\section{Abstract}

Case notes of 1113 consecutive new patients referred to a consultant ophthalmologist at a district general hospital were reviewed to determine the source and efficacy of referrals and the current screening practices of general practitioners and ophthalmic opticians. General practitioners initiated referral in 546 cases $(49 \%)$ and ophthalmic opticians referral in $439(39 \%)$. Visual loss or visual disturbance was the most important single reason for referral ( 345 cases; $31 \%$ ), followed by suspected glaucoma (145 cases; $13 \%)$, abnormalities of binocular vision $(140 ; 12.5 \%)$, disorders of eyelids or ocular adnexa $(127 ; 11 \%)$, and red eye $(86 ; 8 \%)$. General practitioners referred many more patients with disorders of the eyelids and adnexa and ophthalmic opticians many more patients with suspected glaucoma. Ophthalmic opticians were far more likely than general practitioners to refer patients with suspected glaucoma correctly.

A total of 180 patients $(16 \%)$ were referred from ocular screening, in 149 cases by ophthalmic opticians and in 10 by general practitioners. Seventy patients had glaucoma or incomplete features of glaucoma, all of them referred by ophthalmic opticians. Of eight diabetic patients referred by ophthalmic opticians, three had asymptomatic disease and in two diabetes was diagnosed as a result of ocular screening. No patient was referred for asymptomatic diabetic retinopathy from screening by general practitioners. Ophthalmic opticians were more likely than general practitioners to diagnose retinopathy requiring photocoagulation.

Use of a community based service to screen for glaucoma could save unnecessary consultant outpatient appointments. A similar service could facilitate detection of diabetic retinopathy at a stage when treatment is most effective.

\section{Introduction}

Since 1948 sight tests have been available without charge to the general public, initially through the Ophthalmic Supplementary Service and since 1975 through the General Ophthalmic Service. Most sight tests are undertaken by ophthalmic opticians $(87 \cdot 5 \%$ in 1985-6) ${ }^{1}$ and the remainder by ophthalmic medical practitioners. Ophthalmic opticians have a statutory duty under the Opticians Act 1958 and the ensuing General Optical Council rules to refer patients with injury or diseases of the eye to a general medical practitioner, and under the NHS (General Ophthalmic Service) Amendment Regulations 1985 to inform the general practitioner of any abnormality of the eyes. Evidence from studies suggests that the General Ophthalmic Service is a main source of referrals to the hospital eye service, particularly with respect to glaucoma. ${ }^{2-4}$ Legislation within the current Health and Medicines Bill, however, proposes to abolish the free NHS sight test for all but certain minority groups. Though the planned legislation was thwarted in the House of Lords, there is no evidence of change in the government's attitude. If the bill is ultimately passed the amount of screening now undertaken will almost certainly decline.
This study aimed at investigating referral practices to the outpatient clinic of a consultant ophthalmologist and at identifying the current screening practices of ophthalmic opticians and general practitioners, particularly with respect to the diagnosis of glaucoma and diabetic retinopathy. An appreciation of the pattern of referrals and of the present effectiveness of screening will help guide any changes in practice that may become necessary should the free sight test be abolished.

\section{Methods}

From 1 November 1986 to 31 December 1987, 1437 patients were referred to a consultant ophthalmologist at Burton District Hospital Centre. On the basis of the referral letters patients were allocated urgent, semiurgent, or non-urgent appointments. The case notes of 1113 of these patients were reviewed. The remaining 324 patients had not been seen by the time the study was concluded.

Most of the patients were seen by a single consultant ophthalmologist and the remainder by a clinical assistant or one of several senior house officers. The sample comprised all routine referrals from general practitioners, hospital doctors (mostly consultants), and community medical officers. A few emergency referrals were included if the patients had been seen originally in the clinic; those initially seen outside clinic times or referred from the casualty department were not included. Many outpatient attendances were initiated by ophthalmic opticians, who referred patients via the general practitioner. General practitioners were requested to include a copy of the optician's report, usually on form GOS18, with their referral letter.

Biographical data were obtained from the case notes, including sex, age at time of attendance, and source of referral - that is, general practice, ophthalmic optical or ophthalmic medical practice, hospital doctor, or community medical officer. The referral letters were analysed for reports of symptoms and the primary and secondary reasons for referral. The reason for referral was classified by using a system devised for the study which was based on symptoms and anatomical location. Referral data were also analysed for the types of examinations undertaken by the referring agentfor example, assessment of visual acuity, ophthalmoscopy, assessment of binocular vision, visual field examination (including type of visual field test), measurement of intraocular pressure, and fluorescein staining of the cornea. The ocular diseases of each patient were classified according to the International Classification of Diseases (9th revision) and the extended five digit code "Classification of disorders of the eye" proposed by the International Council of Ophthalmology. Finally, the clinical action taken by the ophthalmologist was recorded.

In the assessment of the role of ophthalmic opticians and general practitioners in screening for ocular disease patients were classified as those with or without symptoms based on information in the referral letter and the history taken by the ophthalmologist. Patients were deemed not to have symptoms if they were unaware of any ocular abnormalities apart from those attributable to refractive error, and referral of these 
patients was considered to be a consequence of some form of ocular screening. The few older children with squint could be classified as having asymptomatic disease if a reliable history was obtained, but younger children could not be classified in this way.

Diagnosis of glaucoma and borderline conditions - The criteria for diagnosis of ocular hypertension were intraocular pressure $>21 \mathrm{~mm} \mathrm{Hg}$, no evidence of angle closure, and normal visual fields. Borderline findings were suspicion of disc cupping but no definite glaucomatous field loss. If anatomically narrowed anterior chamber angle was present this was noted in relation to either raised intraocular pressure or borderline findings. Glaucoma was defined as glaucomatous field loss together with optic disc cupping or raised intraocular pressure, or both

\section{Results}

Of the 1113 patients whose case notes were reviewed, 467 were male and 646 female. As expected, the age distribution (table I) was bimodal with a greater proportion of children and elderly patients.

REFERRAL PATTERNS

\section{Referring agents and reasons for referral}

General practitioners initiated the referrals of 546 patients (49\%) and ophthalmic opticians the referrals (initially to the general practitioner) of 439 (39\%). Of the remaining patients, $88(8 \%)$ were referred by other hospital doctors, $23(2 \%)$ by community medical officers, and four referrals were initiated by ophthalmic medical practitioners (see table II). The referrals initiated by general practitioners originated from 40 practices, 10 of which accounted for 287 patients (53\%). Referrals initiated by ophthalmic opticians originated from 24 practices, seven of which accounted for 275 patients $(63 \%)$

Table II lists the referring agents and the reasons for referral. Visual disturbance or loss was the most important reason for referral ( 345 cases; $31 \%$ ), followed by suspected glaucoma $(145 ; 13 \%)$ and abnormalities of binocular vision, mainly squint $(140 ; 13 \%)$.

TABLE I-Age distribution of patients studied

\begin{tabular}{lcccccccccccc}
\hline Age (years): & $0-$ & $10-$ & $20-$ & $30-$ & $40-$ & $50-$ & $60-$ & $70-$ & $80-$ & $\geqslant 90$ & Unknown & Total \\
No of patients: & 200 & 67 & 58 & 69 & 106 & 109 & 208 & 173 & 103 & 8 & 12 & 1113
\end{tabular}

TABLE II - Referring agents and primary reasons for referral
Disorders of the eyelids or ocular adnexa accounted for 127 referrals $(11 \%)$ and red eye for a further $86(8 \%)$.

Reasons for referral differed substantially among the referring agents. General practitioners referred 107 $(84 \%)$ of the patients with disorders of the eyelids or ocular adnexa and $66(77 \%)$ of the patients with red eye, whereas ophthalmic opticians referred $118(81 \%)$ of the patients with suspected glaucoma. Half of the cases of suspected squint were referred by general practitioners as compared with roughly a third by ophthalmic opticians and a fifth by hospital doctors and community medical officers.

The type of information in the referral letter also varied with the referring agent. Ophthalmic opticians were more likely than general practitioners to provide details of an ophthalmic examination and indicate the anatomical location of the problem. Failure by ophthalmic opticians to specify an anatomical location occurred in two out of 17 referrals for red eye and 17 out of 168 referrals for visual loss. Failure by general practitioners to specify an anatomical location occurred in 26 out of 66 referrals for red eye (39\%) and 41 out of 133 referrals for visual loss (31\%). As expected, a report of visual acuity was provided in all referrals initiated by ophthalmic opticians, whereas the general practitioners provided this information for only 28 patients $(21 \%)$ referred for visual disturbance or visual loss.

Of the 324 patients who were unable to obtain appointments during the study period, only 32 had suspected glaucoma, squint, or red eye, priority appointments having been given to patients with these conditions. Visual loss, mostly due to cataract or retinal disease, accounted for 202 of the 324 referrals $(62 \%)$, followed by disorders of the eyelids or ocular adnexa $(39 ; 12 \%)$.

\section{Accuracy of referral}

The accuracy of referral was assessed by comparing the primary and secondary (if any) reasons for referral with the final diagnosis (table III). The reason for referral was considered appropriate if the diagnosis suggested by the referring agent was confirmed by the ophthalmologist or if both the symptoms reported and the designated anatomical location of the problem corresponded to the final diagnosis. Ophthalmic opticians were far more likely to refer patients with glaucoma correctly (96 cases; $80 \%$ ) than were general

\begin{tabular}{|c|c|c|c|c|c|c|c|c|}
\hline \multirow[b]{2}{*}{ Reason for referral } & \multicolumn{7}{|c|}{ Referring agent } & \multirow[b]{2}{*}{ Total } \\
\hline & $\begin{array}{c}\text { General } \\
\text { practitioner }\end{array}$ & $\begin{array}{l}\text { Ophthalmic } \\
\text { optician }\end{array}$ & $\begin{array}{l}\text { Ophthalmic } \\
\text { medical } \\
\text { practitioner }\end{array}$ & $\begin{array}{c}\text { Hospital } \\
\text { doctor }\end{array}$ & $\begin{array}{l}\text { Community } \\
\text { medical officer }\end{array}$ & Other & Unknown & \\
\hline Suspected glaucoma & 25 & 118 & 2 & & & & & 145 \\
\hline \multicolumn{9}{|l|}{ Red eye: } \\
\hline Conjunctiva & 29 & 6 & & 1 & & & & 36 \\
\hline Cornea & 4 & 7 & & & & & & 11 \\
\hline Uvea & 5 & 1 & & & & & & $6\} 86$ \\
\hline Sclera & 2 & 1 & & & & & & 3 \\
\hline Unknown & 26 & 2 & & 1 & & 1 & & $30]$ \\
\hline Lids/adnexa & 107 & 9 & & 9 & & 2 & & 127 \\
\hline \multirow{2}{*}{\multicolumn{9}{|c|}{ Visual disturbance/visual loss: }} \\
\hline & & & & & & & & \\
\hline Cornea & 4 & 8 & & & & & & 12) \\
\hline Lens & 39 & 55 & 1 & 8 & & & & 103 \\
\hline Vitreous & 8 & & & & & & & 8345 \\
\hline Retina & 11 & 46 & 1 & 12 & & & & 70 \\
\hline Optic nerve & & 6 & & 1 & & & & 7 \\
\hline Visual pathway & 2 & 1 & & & & & & 3 \\
\hline Other & 24 & 30 & & 2 & & & & 56 \\
\hline Unspecified & 41 & 17 & & 9 & 5 & 1 & & 73 \\
\hline Refraction & 4 & 5 & & 1 & & 3 & & 13 \\
\hline Asymptomatic fundal abnormality & 2 & 47 & & 9 & & & & 58 \\
\hline Headache & 6 & 4 & & 1 & & & & 11 \\
\hline Other & 29 & 12 & & 10 & 1 & 2 & & 54 \\
\hline Rereferral & 92 & 14 & & 7 & 2 & 2 & & 117 \\
\hline Unknown & 16 & 6 & & 4 & 2 & & 2 & 30 \\
\hline Total & 546 & 439 & 4 & 88 & 23 & 11 & 2. & 1113 \\
\hline
\end{tabular}


practitioners (10 cases; $37 \%$ ). Ophthalmic opticians referred patients for assessment of glaucoma if they found physical signs of the disease (optic disc cupping, raised intraocular pressure, loss of visual field), whereas general practitioners mostly referred on the basis of pain, visual loss or haloes, or a positive family history.

The accuracy of referrals for abnormalities of binocular vision, mostly squint, was $61 \%$ ( 28 cases) for ophthalmic opticians and 52\% (40 cases) for general practitioners. General practitioners tended to refer younger children, whereas the ophthalmic opticians were more likely to refer older children who had failed a school sight test.

The accuracy of referrals in cases of red eye by both ophthalmic opticians and general practitioners was low. In 11 cases (a quarter of referrals in which an

TABLE III-Accuracy of referral by general practitioners and ophthalmic opticians expressed as proportion of primary and secondary diagnoses confirmed at ophthalmological outpatient consultation ${ }^{\star}$

\begin{tabular}{|c|c|c|c|}
\hline \multirow[b]{2}{*}{ Reason for referral } & \multicolumn{2}{|c|}{ Referring agent } & \multirow[b]{2}{*}{ Total } \\
\hline & $\begin{array}{c}\text { General } \\
\text { practitioner }\end{array}$ & $\begin{array}{l}\text { Ophthalmic } \\
\text { optician }\end{array}$ & \\
\hline Suspected glaucoma & $\begin{array}{r}10 / 27 \\
8 / 40\end{array}$ & $96 / 120$ & $\begin{array}{l}106 / 147 \\
9 / 55\end{array}$ \\
\hline Conjunctiva & $7 / 29^{8 / 40}$ & $2 / 6^{5 / 15}$ & $9 / 35^{9 / 35}$ \\
\hline Cornea & $0 / 4$ & $3 / 7$ & $3 / 11$ \\
\hline Uvea & $0 / 5$ & $0 / 1$ & $0 / 6$ \\
\hline Sclera & $1 / 2$ & $0 / 1$ & $1 / 3$ \\
\hline Lids/adnexa & $78 / 109$ & $5 / 9$ & $83 / 118$ \\
\hline \multicolumn{4}{|l|}{ Binocular vision } \\
\hline abnormality & $40 / 77$ & $28 / 46$ & $68 / 123$ \\
\hline Visual loss & $59 / 74$ & $138 / 174$ & $197 / 248$ \\
\hline \multicolumn{4}{|l|}{ Visual disturbance/loss: } \\
\hline Cornea & $3 / 4$ & $3 / 8$ & $6 / 12$ \\
\hline Lens & $42 / 43$ & $52 / 59$ & $94 / 102$ \\
\hline Vitreous & $4 / 8$ & & $4 / 8$ \\
\hline Retina & $7 / 11$ & $36 / 48$ & $43 / 59$ \\
\hline Optic nerve & & $2 / 6$ & $2 / 6$ \\
\hline Visual pathway & $0 / 2$ & $0 / 1$ & $0 / 3$ \\
\hline Refraction & $2 / 4$ & $2 / 5$ & $4 / 9$ \\
\hline \multirow{2}{*}{$\begin{array}{l}\text { Asymptomatic fundal } \\
\text { abnormality }\end{array}$} & & & \\
\hline & $1 / 2$ & $43 / 47$ & $44 / 49$ \\
\hline
\end{tabular}

*Table includes primary and secondary reasons for referral. Hence figure do not correspond to those in table II.

TABLE IV-Diagnoses of 58 patients with unspecified visual loss referred by general practitioners and ophthalmic opticians

\begin{tabular}{lccr}
\hline & \multicolumn{2}{c}{ Referring agent } & \\
\cline { 2 - 3 } Diagnosis & $\begin{array}{c}\text { General } \\
\text { practitioner }\end{array}$ & $\begin{array}{c}\text { Ophthalmic } \\
\text { optician }\end{array}$ & Total \\
\hline No abnormality & 6 & 7 & 13 \\
Refractive error & 2 & & 2 \\
$\begin{array}{l}\text { Binocular vision abnormality including } \\
\quad \text { amblyopia }\end{array}$ & 2 & 3 & 5 \\
Cataract & 8 & & 8 \\
Macular degeneration & 3 & 1 & 4 \\
Retinal vascular occlusion & 6 & 2 & 8 \\
Optic nerve abnormality & 3 & & 3 \\
Other retinal abnormality & 1 & 4 & 14 \\
Other & 10 & 17 & 58 \\
\hline Total & 41 & & \\
\hline
\end{tabular}

TABLE $\mathrm{V}-$ Reasons for referral and referring agents in 122 patients found to have no appreciable abnormality at ophthalmological outpatient consultation

\begin{tabular}{|c|c|c|c|c|c|}
\hline \multirow[b]{2}{*}{ Reason for referral } & \multicolumn{3}{|c|}{ Referring agent } & \multirow[b]{2}{*}{ Unknown } & \multirow[b]{2}{*}{ Total } \\
\hline & $\begin{array}{c}\text { General } \\
\text { practitioner }\end{array}$ & $\begin{array}{l}\text { Ophthalmic } \\
\text { optician }\end{array}$ & $\begin{array}{c}\text { Hospital } \\
\text { doctor and } \\
\text { community } \\
\text { medical officer }\end{array}$ & & \\
\hline Squint & 21 & 4 & 9 & & 34 \\
\hline Lids/adnexa & 11 & & & & 11 \\
\hline Red eye & 8 & 2 & & 1 & 11 \\
\hline Suspected glaucoma & 3 & 14 & & & 17 \\
\hline Visual loss, unspecified & 6 & 7 & 2 & 1 & 16 \\
\hline Visual loss, vitreous, retina, optic nerve & 1 & 7 & & & 8 \\
\hline Other & 12 & 8 & 5 & & 25 \\
\hline Total & 62 & 42 & 16 & 2 & 122 \\
\hline
\end{tabular}

anatomical lesion was specified) no abnormality could be found, presumably because the condition had resolved by the time that the patient was seen in the clinic. Most of the remaining false positive referrals for red eye were because of incorrect location of the primary disorder.

Ophthalmic opticians and general practitioners referred broadly comparable numbers of patients with visual loss due to cataract. The accuracy of referral for cataract was lower for ophthalmic opticians ( 52 of 59 cases; $88 \%)$ than for general practitioners $(42 / 43 ; 98 \%)$ because the opticians tended to refer patients with cataract that was not considered clinically significant.

Many more patients with diseases of the posterior segment of the eye were referred by ophthalmic opticians than by general practitioners, and in nearly half of the referrals by ophthalmic opticians the presenting condition was asymptomatic. Though accuracy of referral was comparable in cases in which an anatomical location was specified, general practitioners were far more likely to refer patients with visual loss for unspecified reasons (41 patients; 13 found to have abnormality of posterior segment) (table IV) than were opticians (17 patients).

The most common reason for referral in the 122 patients $(11 \%)$ subsequently found to have no appreciable disease (table V) were abnormalities of binocular vision (mostly squint), suspected glaucoma, and visual disturbances or visual loss.

\section{SCREENING FOR OCULAR DISEASE}

One hundred and eighty (16\%) of the 1113 patients in the series were classified as not having symptoms and so may be assumed to have been referred as a result of screening. Most of them were referred by ophthalmic opticians (149 cases) and the remainder by general practitioners (10), other hospital consultants (13), community medical officers (five), or other agents (three). Table VI lists the referring agents and primary diagnoses in these cases. Interestingly, all referrals for asymptomatic glaucoma were initiated by ophthalmic opticians. The remaining patients presented with various conditions; but to examine the roles of ophthalmic opticians and general practitioners in screening for eye disease we analysed patients with glaucoma and diabetic retinopathy.

\section{Glaucoma}

There were 70 referrals for suspected asymptomatic glaucoma and a further 77 for symptomatic disease. Of these, 120 were initiated by ophthalmic opticians and 27 by general practitioners. Glaucoma was confirmed in 33 cases ( 20 asymptomatic) and borderline glaucoma or ocular hypertension in a further 73 (48 asymptomatic). The diagnosis was confirmed in $96(80 \%)$ of the referrals from ophthalmic opticians but in only 10 (37\%) cases referred by general practitioners. All patients referred by general practitioners had symptoms. From information in the referral letters we attempted to assess the diagnostic procedures undertaken by the opticians and general practitioners (table VII). Ophthalmic opticians reported intraocular pressure measurements in 52 of the 96 referrals (54\%) in which glaucoma or features of borderline glaucoma were confirmed. The remaining patients were referred for suspicious optic disc cups, loss of visual field, or other clinical features. General practitioners referred patients with suspected glaucoma primarily on the basis of symptoms. Overall an ocular examination was reported in less than one third of the patients referred.

Suspected glaucoma was not confirmed by the ophthalmologist in 24 patients referred by ophthalmic opticians and 17 referred by general practitioners (table VII). Among the unconfirmed cases referred by the opticians raised intraocular pressure was the 


\begin{tabular}{|c|c|c|c|c|c|}
\hline \multirow[b]{2}{*}{ Primary diagnosis } & \multicolumn{4}{|c|}{ Referring agent } & \multirow[b]{2}{*}{ Total } \\
\hline & $\begin{array}{l}\text { Ophthalmic } \\
\text { optician }\end{array}$ & $\begin{array}{c}\text { General } \\
\text { practitioner }\end{array}$ & $\begin{array}{c}\text { Hospital } \\
\text { doctor }\end{array}$ & $\begin{array}{l}\text { Community } \\
\text { medical officer }\end{array}$ & \\
\hline Suspected glaucoma/glaucoma & 70 & & & & 70 \\
\hline Diabetic retinopathy & 3 & & 7 & & 10 \\
\hline Squint/amblyopia & 6 & 2 & 1 & 2 & 11 \\
\hline Refractive error & 6 & 1 & & 1 & 8 \\
\hline Corneal abnormality & 4 & & & & 4 \\
\hline $\begin{array}{l}\text { Congenital abnormalities of anterior } \\
\text { segment }\end{array}$ & 2 & & & & 2 \\
\hline Choroidal naevus & 8 & & & & 8 \\
\hline Macular degeneration & 7 & & & & 7 \\
\hline Other abnormalities of retina & 13 & & & & 13 \\
\hline Optic disc abnormalities & 3 & 1 & & & 4 \\
\hline $\begin{array}{l}\text { Congenital abnormalities of posterior } \\
\text { segment }\end{array}$ & 4 & & & & 4 \\
\hline Others & 5 & 1 & 2 & & 8 \\
\hline No abnormality found & 18 & 5 & 3 & 2 & 28 \\
\hline Total & 149 & 10 & 13 & 5 & $177^{\star}$ \\
\hline
\end{tabular}

ॠThree patients referred by other agents omitted from table.

TABLE VII - Diagnostic procedures for glaucoma employed by ophthalmic opticians and general practitioners *

\begin{tabular}{|c|c|c|c|c|}
\hline & \multicolumn{2}{|c|}{ Ophthalmic opticians } & \multicolumn{2}{|c|}{ General practitioners } \\
\hline & $\begin{array}{l}\text { Diagnosis } \\
\text { confirmed }\end{array}$ & $\begin{array}{c}\text { Normal or } \\
\text { other } \\
\text { diagnosis }\end{array}$ & $\begin{array}{l}\text { Diagnosis } \\
\text { confirmed }\end{array}$ & $\begin{array}{c}\text { Normal or } \\
\text { other } \\
\text { diagnosis }\end{array}$ \\
\hline Ophthalmoscopy & 20 & 4 & 3 & 3 \\
\hline Visual fields & & & & 1 \\
\hline Ophthalmoscopy and visual fields & 8 & 3 & 1 & \\
\hline Ophthalmoscopy, visual fields, and intraocular pressures & 14 & 3 & & \\
\hline Ophthalmoscopy and intraocular pressures & 17 & 1 & & \\
\hline Visual fields and intraocular pressures & 10 & 1 & & \\
\hline Intraocular pressures & 11 & 3 & & \\
\hline Unknown & 16 & 9 & 6 & 13 \\
\hline 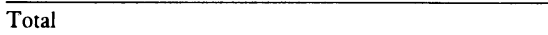 & 96 & 24 & 10 & 17 \\
\hline
\end{tabular}

^Table includes primary and secondary reasons for referral. Hence figures do not correspond to those in table II.

principal factor in only nine, the others being referred because of suspicious ophthalmoscopic appearances or reduced visual fields. Among the unconfirmed cases referred by general practitioners ophthalmoscopy or visual field examination was the basis for referral in four, the remainder being referred for suspicious symptoms.

\section{Diabetic retinopathy}

There were only 36 patients in whom the primary diagnosis was diabetic retinopathy, and 20 of them were referred from diabetic clinics by consultant physicians as a presumed result of screening. Six, however, were referred by general practitioners, and in eight others the referral was initiated by ophthalmic opticians. Three of the patients referred by ophthalmic opticians did not have symptoms, and in two cases diabetes was diagnosed only after these ocular complications had been discovered. All six patients referred by general practitioners had symptoms, but one of them was not a known diabetic and was diagnosed as a result of the referral. All referral letters from opticians gave funduscopic findings but funduscopy was reported in only two cases referred by general practitioners. Patients referred by ophthalmic opticians and consultant physicians were much more likely to need laser treatment than those referred by general practitioners.

\section{Discussion}

When we compared the referral patterns of general practitioners and ophthalmic opticians some clear trends emerged. Nearly one third of referrals by general practitioners alone were for disorders of the external eye or ocular adnexa compared with only $6 \%(26 / 439$ ) for referrals initiated by the opticians. General practitioners were also more likely to refer cases of suspected squint. By contrast, referrals of patients with suspected glaucoma and to a less extent visual loss were far more likely to be initiated by the opticians. Ophthalmic opticians were also far more likely to refer disorders of the retina or optic disc and general practitioners to refer patients with visual loss for unspecified reasons. There was little evidence that general practitioners screened for glaucoma or diabetic retinopathy, whereas ophthalmic opticians screened for glaucoma with considerable skill and also initiated referrals of several patients with previously unrecognised diabetic retinopathy.

These differences in referral patterns are due to several factors. Patients with symptoms due to external ocular disease generally visit their general practitioner, but when suffering from visual loss they frequently visit an optician in the belief that they need new glasses. General practitioners do not usually undertake funduscopy, or at least do not report their findings in the referral letters, whereas funduscopy is a routine part of the NHS sight test. As a consequence ophthalmic opticians are more likely to detect abnormalities of the posterior segment of the eye. Ophthalmic opticians conduct ocular examinations, maintaining a high degree of vigilance for asymptomatic conditions such as glaucoma. They are obliged to refer a patient in whom they find an abnormality without making a diagnosis. General practitioners rarely screen for ocular disease but usually refer patients with ocular symptoms and often suggest a diagnosis without providing details of an ocular examination. In general the accuracy of the opticians' examinations was higher than the analysis of diagnostic accuracy suggested, the discrepancy largely being due to a difference in the clinical importance attributed to the findings of the ophthalmologist.

The quality of referrals to a consultant is important for the service provided. Where the service is overstretched, as in the outpatient department in this study and in many throughout Britain, any reduction in the accuracy of referrals will have serious consequences. Time spent on patients referred inappropriately will further delay the treatment of those who genuinely need specialist attention, some of whom have conditions which without treatment may lead to irreversible loss of vision. Priorities can be decided only if the referral letters contain reasonably detailed and accurate information, which was by no means always the case. Improvements in the accuracy of referrals need to be directed towards reducing the number of false positive referrals and improving the quality of true positive referrals. The most important reasons for false positive referrals in this study were suspected squint and glaucoma; greater utilisation or development of community based screening programmes could reduce the false positive referral rate.

At present the nearest approach to a screening service for ocular disease is provided by ophthalmic opticians. Under the terms and conditions of service ophthalmic opticians providing NHS sight testing are obliged to inform the general practitioner of any abnormality in the eyes. Thus in addition to refraction, the optician routinely performs an ophthalmic examination that includes funduscopy. In recent years many ophthalmic opticians have also acquired equipment for measuring intraocular pressures ${ }^{5}$ and, less commonly, for the accurate assessment of visual fields. Much screening is therefore undertaken in the context of the NHS sight test, though this screening, particularly for glaucoma, has undergone spontaneous growth without planning or policy agreement between the General Ophthalmic Service and the hospital eye services. In the white paper Promoting Better Health, outlining the government's proposals in the Health and Medicines Bill, the government contends that "without the constraints imposed by the NHS contract, ophthalmic opticians will be free to offer either a standard sight test 
or a fuller eye examination to meet their patients' needs and preferences." 6 This seems to imply that ophthalmic opticians would no longer be under an obligation to provide anything more than a routine refraction test and that any form of ocular screening would be confined to those willing and able to pay an additional fee.

In our study two thirds of all correct referrals for glaucoma occurred as a result of current screening practices by ophthalmic opticians. Other studies have also shown that opticians are a main source of referrals for glaucoma ${ }^{24}$ and that general practitioners refer only patients with symptoms. Though the consequences of the proposed loss of the NHS funded sight test are difficult to predict, it is reasonable to assume that the number of patients seen by ophthalmic opticians will fall. This will probably have little impact on referrals for squint or red eye, but referrals for asymptomatic conditions that are detected during the routine sight test are likely to decline. This may reduce the number of referrals for trivial conditions such as minor abnormalities of the fundus or mild ocular hypertension, but there will also be a reduction in referrals of patients with early asymptomatic glaucoma and as a consequence an increase in patients presenting with advanced, symptomatic disease.

Chronic simple glaucoma is a common disorder, insidious, progressive, and irreversible, affecting between $0.5 \%$ and $1.0 \%$ of the population over $40,,^{78}$ and is asymptomatic until visual loss is far advanced. It affects $150000-300000$ people and is responsible for about $12 \%$ of the registered blind in England and Wales. ${ }^{9}$ Medical and surgical treatment have a proved effect in slowing its progression. ${ }^{11}{ }^{11} \mathrm{~A}$ reduction in the current amount of screening for glaucoma as a result of the proposed legislation may well result in delayed diagnosis with serious results for the patient. Establishment of a planned glaucoma screening service, with agreement between ophthalmologists and ophthalmic opticians on the screening tests and criteria for referral, could both reduce the incidence of blindness from the disease and relieve demand on the hospital eye services.

Using data from our study we can attempt to assess the impact of such a glaucoma screening service. Referral would have been avoided for most of the 41 false positive referrals for glaucoma and for most of the 73 patients with ocular hypertension or borderline findings. Thus a community based screening service might have saved nearly 100 new outpatient appointments a year and would have had an even greater impact on follow up appointments. Based on the average age of our patients with ocular hypertension or borderline findings the life expectancy of these patients from life tables is about 16 years. Given a constant rate of referral, we could expect 1550 follow up outpatient appointments a year. Only a minority of these patients will develop glaucoma, and thus a glaucoma screening service could save over 1000 follow up appointments a year. The cost of the NHS sight test is $£ 9.75$, whereas the cost of a hospital outpatient appointment is about £30. If the money which the government proposes to withdraw from the NHS sight test was diverted to a comprehensive glaucoma screening service the standard of glaucoma screening would improve and the waiting times for outpatient appointments would fall without additional cost. The unknown quantity is the number of patients currently undiagnosed, but even if this was twice the number found in this study - that is, 66 rather than 33 -there would still be a reduction in the number of referrals for glaucoma.

Though screening for glaucoma may detect early cases, it presents a serious problem. Three diagnostic procedures are required to diagnose glaucoma reliably: funduscopy to assess the optic disc, tonometry to measure intraocular pressures, and instrumentation to assess visual fields. Without all three, screening processes generate appreciable numbers of false positive and false negative cases. The most problematic aspect has until recently been the assessment of visual fields. Screening without visual field assessment will not only detect patients with glaucoma but also identify a much larger population with incomplete features of the disease. As studies have shown that patients with ocular hypertension or suspicious disc cupping are at definite risk of glaucoma ${ }^{12}$ this population cannot be ignored. Any widespread glaucoma screening with referral criteria that excluded assessment of visual fields would generate large numbers of cases of incomplete glaucoma and place enormous extra pressures on hospital eye services. The development of computerised central field analysers in which the test field is compared automatically with parameters from a series of normal fields, however, has made visual field screening a realistic objective, and agreed criteria for referral could be established while other patients with lesser abnormalities could be kept under review in the screening clinic.

Diabetic retinopathy remains the commonest cause of blindness in the young and middle aged in the United Kingdom, but effective treatment is available and early detection offers the best hope of a successful outcome. Though funduscopy is performed routinely on many patients attending diabetic clinics, fewer than half of all known diabetics attend these clinics. ${ }^{13}$ Most remain under the sole care of their general practitioners and are much less likely to have regular funduscopy. We believe that the pattern of diabetic care in the Burton area is representative of the pattern nationally. Thirty six patients with diabetic retinopathy were referred during the 14 months of the study. Almost a quarter of these referrals were initiated by ophthalmic opticians performing routine eye tests. All the patients referred by general practitioners alone had symptoms, and there was no indication that these referrals resulted from routine screening.

The issue of who should screen for diabetic retinopathy has inevitably arisen. Studies show that ophthalmic opticians have the necessary skills to detect diabetic retinopathy at a treatable stage, ${ }^{14}$ but though they are participating in screening programmes in several centres in the United Kingdom, ${ }^{15}$ their role remains controversial. Scott and Flanagan stated that most referrals from opticians were for lesions that were of no clinical importance-a view not substantiated by our study-and considered it exceptionally rare for diabetes to be detected by finding retinopathy in a person not known to be suffering from the disease ${ }^{16}$ In our study, though numbers were small, a quarter of patients referred by ophthalmic opticians for retinopathy were undiagnosed diabetics, and more than half the patients referred required laser treatment.

Arguably general practitioners should take more responsibility for screening for diabetic retinopathy, ${ }^{17}$ but general practitioners with an average of only about 20 diabetics on their lists are unlikely to gain the experience necessary to provide an effective screening service. ${ }^{17}$ Unless studies showed that a substantial number of general practitioners could be (or were willing to be) trained in diagnosing early diabetic retinopathy the employment of community based specialists - either ophthalmic opticians or ophthalmic medical practitioners-would remain a more acceptable alternative.

Objections have been raised to mixing the commercial aspects of selling glasses with the primary care of patients, with the concern that screening for glaucoma or diabetic retinopathy may expand into the marketplace. ${ }^{16}$ If the screening aspects of the NHS sight test were separated from refraction tests there would be 
greater flexibility in the delivery of screening services, allowing, for example, the employment of ophthalmic medical practitioners in health centres or general practices. Undoubtedly there are also some ophthalmic opticians who find the clinical aspects of their work more interesting than the commercial and who would be willing to devote some of their time to ophthalmic screening within a general medical practice. Given the limited amount of undergraduate and postgraduate training in ophthalmology that most doctors receive, the complexity of the specialty and its dependence on expensive diagnostic equipment, and the general practitioner's commitments to many other aspects of medicine, it seems unlikely that most general practitioners would be able to take on this role.

French CN. Ideal average times for sight test. Optometry Today 1987;27:741-3. 2 Steinman WC. The "who" and "how" of detecting glaucoma. Br Med $\mathcal{f}$ 1982;285:1091-3.

3 MacKean M, Elkington AR. Referral routes to hospital with chronic open angle glaucoma. Br Med f 1982;285:1093-5.

4 Clearkin L, Harcourt B. Referral pattern of true and suspected glaucoma to an adult ophthalmic outpatient clinic. Trans Ophthalmol Soc UK 1983;103: 284-7.

5 Tuck M. Early detection of glaucoma - an International Glaucoma Association survey. Optician 1987;195:12-8.

6 Department of Health and Social Security. Promoting better health. The government's programme for improving primary health care. London: $\mathrm{HMSO}$ 1987:33.

7 Hollows FC, Graham PA. Intra-ocular pressure, glaucoma and glaucoma suspects in a defined population. Br f Ophthalmol 1966;50:570-86.

8 Bengtsson B. The prevalence of glaucoma. Br J Ophthalmol 1981;65:46-9.

9 Crick RP. Computerised clinical data base for glaucoma-ten years' experience. Research in Clinical Forums 1980;2:29-39.

10 Watson PG, Grierson I. The place of trabeculectomy in the treatment of glaucoma. Ophthalmology 1981;88:175-96.

11 Sponsell WE, Dallas NL, Burbridge L. Visual field survival: the response to timolol therapy in open-angle glaucoma. Br $f$ Ophthalmol 1983;67:220-7.

12 Perkins ES. The Bedford glaucoma survey. 1. Long-term follow up of borderline cases. Br $\mathcal{O}$ Ophthalmol 1973;57:179-92.

13 Yudkin JS, Boucher BJ, Schopflin KE, et al. The quality of diabetic care in a London health district. $f$ Epidemiol Community Health 1980;34:277-80.

14 Burns-Cox CJ, Dean-Hart JC. Screening of diabetics for retinopathy by ophthalmic opticians. BrMed $\mathcal{F}$ 1985;290:1052-4.

15 Kopelman P, Keable-Elliot D. Charging patients for eye tests. Br Med $\mathcal{J}$ 1988;296:719.

16 Scott JD, Flanagan D. Charging patients for eye tests. Br Med $\mathcal{f} 1988 ; 296$ 290-1.

17 Yudkin JS. Charging patients for eye tests. Br Med $\mathcal{F}$ 1988;296:64.

(Accepted 13 September 1988)

\title{
Mastectomy or conservation: the patient's choice
}

\author{
Ronald G Wilson, Alison Hart, P J D K Dawes
}

\section{Abstract}

Study objective-To determine whether, if given the choice, patients with breast cancer would prefer mastectomy or conservation treatment, neither treatment having been shown to be preferable.

Design-Non-randomised case series with 28 patients interviewed after two years and all followed up.

Setting-Secondary care referral centre.

Patients -153 women, aged less than 65 , with $T_{1}$, $T_{2}, N_{1}$, and $N_{0}$ tumours of the breast given the choice of treatment (that is, all eligible patients from December 1979).

Interventions-Patients were asked, after information and counselling, which treatment they would prefer. The chosen treatment was given without further question. Mastectomy included node sampling and local radiotherapy if indicated. Conservation treatment comprised excision of the lump, external radiotherapy, and irridium wire implant to tumour bed.

Main results-Conservation treatment was chosen by 54 women and mastectomy by 99 . Reasons for preferring mastectomy included desire for rapid treatment for domestic or employment reasons and fear of possibility of future mastectomy. Only two of the sample interviewed regretted their choice. During limited follow up no advantages to either form of treatment were seen in terms of recurrence or survival.

Conclusions-Patients with breast cancer are capable of choosing treatment and should play a part in deciding which treatment to have. They do not automatically choose to retain the breast.

Newcastle General

Hospital, Newcastle upon

Tyne NE4 6BE

P J D K Dawes, FRCR, consultant radiotherapist and oncologist

Alison Hart, medical student

R G Wilson, FRCS, consultant surgeon and surgical oncologist

Correspondence to: Mr Wilson. lymph nodes and, generally, a booster dose to the tumour bed..$^{2}$ As this treatment offers a good cosmetic result and has not been shown to be less effective than mastectomy its proponents say that it is better than a mutilating operation. Conservation is not synonymous with conservative surgery, in which the surgery is usually a segmental or partial mastectomy with or without adjuvant radiotherapy and a good cosmetic result is not usually possible.

Whether conservation treatment is acceptable to women with breast cancer or indeed is demanded by them, as suggested by its supporters, and whether it results in the same rate of cure as mastectomy are not known. It is not a new concept but became more common after a report in 1980 of a seven year follow up of patients who had received it in France. ${ }^{3}$ That study, which was not a controlled trial, showed that for small tumours conservation treatment gave results almost identical with those achieved by mastectomy. Larger tumours, however, had an unacceptably high rate of local recurrence. A proper trial comparing mastectomy with conservation has still not been done. The trial of Fischer $e t a l,{ }^{4}$ which is much quoted, studied conservative surgery comprising segmental mastectomy with axillary dissection plus radiotherapy for nodal disease and adjuvant chemotherapy.

A few patients had conservation treatment in this hospital in the 1960s and early 1970s, and by 1979 we made it routinely available to women attending the breast clinic. We wanted to compare the results of the treatments, but we were reluctant to use random allocation to conservation or mastectomy because we thought that this might distress the patients and thereby increase the currently low psychological morbidity in the unit. ${ }^{5}$ These reservations were later justified when an attempt by the Medical Research Council's clinical research centre to do just such a trial failed for these reasons. ${ }^{6}$ If, as Pierguin et al said, the two treatments are equally effective for small tumours ${ }^{3}$ we could not advise women that one was preferable. We therefore offered the two alternatives and asked women to select their treatment. We report the outcome of this policy over the past nine years in terms of both the women's preferences and the results of the treatments. The first 17 patients offered this choice 